\begin{tabular}{|c|c|c|c|c|}
\hline $\begin{array}{c}\text { REVISTA ENTORNO } \\
\text { GEOGRÁFICO }\end{array}$ & $\begin{array}{c}\text { Julio/ } \\
\text { Diciembre } \\
2019\end{array}$ & $\mathrm{~N}^{\circ} 18$ & pp. 22-45 & $\begin{array}{c}\text { ISSN (en línea): 2382-3518/ ISSN } \\
\text { impreso: 1692-0074 }\end{array}$ \\
\hline
\end{tabular}

DOI: $10.25100 /$ eg.v0i18.8605

(a) $(1) \Theta$

Espacios y Territorios

\title{
Webmapping usado para la gestión del recurso hídrico en la cuenca hidrográfica del río Dagua, Valle del Cauca, Colombia
}

\section{Webmapping used for the management of the water resource in the watershed of the Dagua River, Valle del Cauca, Colombia}

\section{Derly Erazo Navia}

Geógrafa. Grupo de Investigación Territorios, Departamento de Geografía, Universidad del Valle. Santiago de Cali, Colombia.

ORCID: 0000-0002-1700-0010

Correo electrónico: derly.navia@gmail.com

Para citar este artículo: Erazo Navia, D. (2019). Webmapping usado para la gestión del recurso hídrico en la cuenca hidrográfica del río Dagua, Valle del Cauca, Colombia. Entorno Geográfico, (18). DOI: 10.25100/eg.v0i18.8605.

Resumen: El presente artículo hace referencia a la aplicación de tecnología web mappig en la construcción de un geovisor para la gestión del territorio y el recurso hídrico, el cual tiene como fin compartir datos geográficos asociados a la cuenca hidrográfica del río Dagua, localizada en el Valle del Cauca, Colombia. La metodología empleada consistió en procesar y transformar datos geográficos de la cuenca hidrográfica, el uso de formatos de representación geográfica de código abierto y aplicación de la herramienta tecnológica librería para mapeo digital leaflet de javascript. Como resultado se obtuvo la creación de un geovisor web de libre acceso, el cual permite visualizar mapas de información de la cuenca por temas, permitiendo la superposición de capas, la selección de capas de información y la visualización de mapas geográficos. El artículo se centra en la importancia que ha adquirido el uso de las nuevas tecnologías de la información y la comunicación, la aplicabilidad de estas en la generación de 
información geográfica asociada a la cuenca hidrográfica, la identificación de variables y situaciones que afectan la cuenca hidrográfica como unidad de planificación territorial y la aplicabilidad de la tecnología web mapping en la transformación de datos geográficos para llevarlos a la visualización de mapas mediante el uso de internet. Finalmente describe las características del geovisor desarrollado.

Palabras clave: Geografía, Cuenca hidrográfica, datos geográficos, tecnologías de la información, mapeo digital.

Abstract: This paper describes the use of web mapping technology in water resource and territory management. Its purpose is to share geographic data associated to the Dagua river watershed, located in the Valle del Cauca Department, Colombia. The methodology used consisted in 1) processing and transforming geographic data of the watershed, 2) using open source geographic representation formats, and 3)

Recibido: 29 de julio de 2019 applying the digital mapping library "Leaflet" from JavaScript. As a result, an open source geoportal was created, which allows visualizing information maps of the basin by themes, allowing the superposition of layers, the selection of layers of information and the visualization of geographical maps. The article focuses on the importance that the use of new information and communication technologies has acquired their applicability in the generation of geographic information associated with the river basin, the identification of variables and situations that affect the river basin. As a territorial planning unit and the applicability of web mapping technology in the transformation of geographic data to take them to the visualization of maps by the internet. Finally, it describes the characteristics of the developed geovisor.

Keywords: Geography, Drainage basins, Geographical data, information technology, digital mapping.

Aceptado: 12 de octubre de 2019 


\section{INTRODUCCIÓN}

E

uso de las tecnologías y la información

hacen parte de una nueva cultura que se expresa en torno a la virtualidad, la cual requiere de una infraestructura tecnológica que sostenga esta nueva realidad espacial y permita su uso para transformar las condiciones de vida de la población, el funcionamiento del sistema económico, la creación de cultura, las formas de comunicación y relación entre las personas, el funcionamiento de la economía, la educación y la ciencia. Sin embargo, las tecnologías y la información son parte de la cultura solo en algunas sociedades de la actualidad, han transformado la forma en que se relaciona el mundo, internet desde su creación como red informática de alcance global y descentralizada genero cambios al inducir a la población a usar la interactividad que se convierte en necesaria cuando la información es usada para conectar a la población en procesos de difusión y la solución de diversas problemáticas. Para Castells (2003), en una sociedad red, la ciencia y la tecnología son los objetivos de la economía y la sociedad provocando una transformación en la concepción del espacio y el tiempo, estos ejercen dominio en las construcciones de identidad cultural influenciados por la riqueza, el poder y la información creando una nueva estructura social. Si bien la sociedad de la información hace referencia a que existe una sociedad global conectada, dependiente de las tecnologías y entorno a estas funcionan todos los ámbitos de la estructura social, no en todos los países ocurre el mismo desarrollo e inclusión tanto en tecnología como en acceso a la información, en el caso de América latina y más en Colombia la estructura de funcionamiento tiene diferencias con otros países respecto a la influencia de la información en la cultura; primero porque la conectividad y la participación de la población en la sociedad de la información se concentra en los centros poblados y segundo aún existe una parte del territorio que está desconectada, espacios rurales excluidos en cuanto a infraestructura tecnológica y uso de las tecnologías en su vida cotidiana. Por esta razón se puede diferenciar entre un mundo urbano conectado con acceso a la información y un mundo rural sin infraestructura tecnológica y desconectada. Según el último reporte del Ministerio de las Tecnologías de la Información y Comunicación (MinTic- SIUST) para el año 2016, la penetración de internet en el territorio colombiano es del $31 \%$ y hay un total de 15.130.185 suscriptores a internet, según el informe de la International Telecomunication Union ITU en Colombia entre los años 2014 y 2015 el $52.6 \%$ de la población usa computadores, el 55,9 \% tiene acceso a internet y el $82,9 \%$ usa telefonía móvil, en Colombia el porcentaje de personas usando internet en áreas urbanas es del $62.9 \%$ y en áreas rurales el $31.2 \% 3$. Si bien el uso de computadores, la comunicación electrónica, el uso de telefonía celular y la conectividad a internet es una realidad en la cual un gran número de personas están inmersos en los centros urbanos y en áreas donde hay cobertura, hay otros espacios en los cuales la influencia tecnológica es baja por falta de infraestructura o porque las formas de relacionarse no lo requieren, pues aún no ha sido adaptadas a sus prácticas cotidianas el uso de las tecnologías. Sin embargo, es una realidad en Colombia, la producción y consumo de información en distintos ámbitos, pero en lo concerniente a la producción y consumo de información geográfica, son las entidades gubernamentales las que para procesos de 
ordenamiento territorial y planificación con mayor autonomía están usando y produciendo este tipo de información.

La importancia del uso de la información geográfica en el campo de la investigación geográfica en Colombia guarda relación con las realidades antrópicas y naturales que al interactuar construyen el territorio; si bien lo antrópico corresponde a los modos de vida de la población y el uso que han hecho del espacio desde tiempos ancestrales y lo natural entendido como el espacio que proporciona beneficios para la subsistencia y permanencia de la vida humana, los cuales están en constante relación, pero que por influencia del funcionamiento en la estructura de subsistencia humana han provocado un desequilibrios que afectan el medio ambiente. Es por esta razón que surge la preocupación de investigar sobre estos desequilibrios. La geografía por lo tanto cuyo interés es conocer esas relaciones y realidades, a partir del reconocimiento directo o indirecto del territorio, es productora de información, datos georreferenciados y localizados con el fin de construir una realidad de los territorios, reconociendo que hay una necesidad hacia la identificación de problemas que tiene gran impacto territorial y que por su importancia deben ser investigados. El uso de la información geográfica es importante en la gestión de los recursos ambientales y caso específico en la gestión del recurso hídrico por ser vital para la vida humana, estratégico en la oferta de servicios eco sistémicos y de organización en la planificación ambiental.

¿Por qué es importante el uso de la información para investigar en geografía? La tecnología en la sociedad informacional es una herramienta útil que apoya la investigación, la solución de problemas socio espaciales, problemas ambientales, la visualización de realidades que afectan a la población y la contribución de alternativas que permitan a la población usar esa información para fortalecer sus procesos organizativos, además, cuando el interés de la geografía se da sobre temas ambientales, necesariamente esto implica territorios rurales o áreas distantes de las centralidades urbanas. Aunque la "era de la información" tiende a concentrarse en ámbitos urbanos, las investigaciones y el uso de los mapas se han centrado en el análisis a los sistemas de ciudad, servicios para mejorar el sistema de transporte urbano, análisis espaciales al comportamiento antrópico urbano, fenómenos demográficos, patrones de ocupación del suelo entre otros, generan inquietud sobre como pueden ser abordada las áreas rurales, pues estos también están habitados, ocurren procesos sociales y problemáticas socio espaciales, cuando se trata de la influencia de los pobladores inmediatos a los territorios y cuando se trata de actividades económicas de alto impacto negativo al medio ambiente como la extracción de recursos. Es en los espacios rurales donde ocurren las diferentes actividades que permiten la vida en la ciudad tales como el uso de los suelos para la explotación agrícola, el uso de los suelos para la explotación agropecuaria, se localizan las fuentes de agua y se encuentran los recursos que transformados permiten la elaboración de objetos que posteriormente son consumidos en los espacios urbanos, y aún más, la preocupante explotación a gran escala de los recursos minerales y naturales, como sucede con el fenómeno que hoy está siendo objeto de muchas críticas y discusiones que involucran el medio ambiente, la geopolítica y economía global tiene que ver con los recursos naturales y las políticas extractivistas, en donde por mantener un sistema económico de consumo se destruye la naturaleza provocando cambios 
irreversibles en el sistema terrestre, estos como la extracción de Oro y Coltán entre otros minerales que sostienen la existencia de privilegios absurdos en la vida urbana según la capacidad de consumo de las personas.

La alternativa que da la geografía con el uso de los SIG y la difusión de información a través de internet es poder dibujar en la era digital esos territorios rurales, aproximarnos a interpretar la afectación antrópica sobre estos, los espacios rurales quizá no se puedan incluir en la era de la información del modo que sucede en espacios urbanos, porque pensar en una transformación tecnológica en cuanto a infraestructura para el acceso implicaría modificaciones e inversión que quizá los estados no estén en capacidad de pagar, además que no sería positivo pensar en esta transformación porque si de conservar la naturaleza se trata, es mejor que las áreas rurales se mantengan así, desconectadas por bien de las formas de relaciones humanas que allí suceden. Pero si se puede contribuir dibujando estos territorios en lo digital, con la intención de aproximar a la comunidad inmediata que habita estos territorios, a los ámbitos urbanos y a las entidades gubernamentales sobre la importancia de las políticas de regulación en defensa de los ambientes naturales que proporcionan la sostenibilidad de los estilos de vida urbanos. La creación de información geográfica digital, desde sus inicios surgió como respuesta a la necesidad de tener en una base de datos toda expresión de la superficie terrestre, si bien la información ha sido necesaria para tener una imagen representativa de lo que es la superficie terrestre, clasificarla y diferenciarla ha permitido el estudio de diversos fenómenos y el intento de control y administración de estos. El uso de los Sistemas de Información Geográfica (SIG) desde la década de los 80's significo una revolución tecnológica en la disciplina, el uso de la tecnología como herramienta para el análisis espacial, implico una revolución tecnológica que afecto los métodos y técnicas convertidas en estándar digital en el uso informático, tuvieron gran influencia en la revolución intelectual que permitió a la disciplina transformar la forma de estudiar y pensar la realidad espacial. $4 \mathrm{En}$ los inicios fue la creación de software para modelar la realidad con el fin de dar explicaciones a los diversos fenómenos del sistema tierra, en la actualidad con los cambios en los usos de la tecnología y la comunicación se han perfeccionado esos software, incluso ha permitido la creación de industrias dedicada a la gestión y administración de estos datos, pero a su vez, los cambios en la forma de representación y distribución de la información han entrado en la era de lo digital donde la imagen importa, por lo tanto el ciberespacio ha transformado la geografía creando la Neogeografía la cual desde el interés de su estudio está aportando a la construcción de información espacial en mapas digitales, en conjunto con otras ciencias y disciplinas, porque relacionarnos en un mundo global implica que la localización sea cada vez más importante para la gestión de la economía y las influencias geopolíticas a escala global.

Del encuentro entre tecnología y geografía surge una relación con lo que Buzai (2014) denomina la "tercera globalización" cuya naturaleza es ser digital como lo planteo Negroponte (1995). Se fundamenta en la circulación de datos por el ciberespacio a través de internet, los "cibermapas" permiten que los diversos estudios e investigaciones que se hacen sobre porciones de territorio o sobre el ámbito global a diferentes escalas puedan mostrar flujos, procesos, situaciones, problemáticas que surgen a partir de la relación 
entre el ámbito natural y las practicas antrópicas, permitiendo distintos análisis a escala global, local o de un área o territorio definido (Buzai, 2014). La infraestructura de internet permite el uso de diversas aplicaciones en línea relacionadas con la transmisión de datos y la creación de espacios virtuales que permitan la reunión de información, es entonces cuando la geografía en la era de la información adquiere importancia porque es la que va a permitir visualizar esos datos y poder acercarnos a tener una imagen o una interpretación sobre la realidad espacial. La geografía en la era de la información es la que permite mostrarnos la complejidad de la tierra en el ciberespacio, pues en el área que corresponde al mapa global nos puede ilustrar las diversas realidades que la conforman. La cartografía, por lo tanto, es esa expresión artística que permite a la geografía a través de los SIG en la web dibujar la complejidad de los territorios para ser compartidos en el ciberespacio ya sea con finalidad de contribuir a la construcción de ubicaciones sobre las diferentes realidades del sistema tierra, permitir la toma de decisiones o la creación de una red global para el trabajo conjunto entre diversos dibujantes del espacio geográfico en la era digital.

Además, en las dinámicas de la información y en la necesidad de construcción de una infraestructura de datos puede dar solución o acercarnos a estas problemáticas, permitiendo reflexionar sobre la importancia del uso de las tecnologías en temas que involucran los daños a los ecosistemas por las prácticas humanas en áreas geográficas únicas. Por un lado, existe una cultura que se expresa en función de sus modos de vida y usos del espacio que resultan negativos para los ambientes naturales; considerando que lo importante es la conservación de la naturaleza.

También existe una cultura que se expresa en torno a la difusión de información, la transmisión de información en imágenes o texto de las diversas situaciones socio-ambientales que preocupan a entidades gubernamentales, entidades dedicadas a la investigación, activistas y defensores del medio ambiente $\mathrm{y}$ una red de grupos sociales interesados en contribuir al cambio o alternativa en defensa de la naturaleza.

Es el acceso a la información a través de internet a modo de imágenes, texto o vídeo un hecho de gran utilidad, el acceso a la información geográfica a través de internet es una posibilidad para la contribución a la infraestructura de datos espaciales disponibles para buscar, ver y consultar datos geográficos, utilizando sólo una conexión a internet y un navegador, como sucede con la tecnología web SIG que incluye el modelo para "web mapping" el cual permite generar y acceder a información geográfica a través de internet. La red permite la difusión de información geográfica en forma de datos espaciales a través de internet la cual requiere la adaptación de tecnologías que propicien la interactividad y flexibilidad en la web. Los datos geográficos son el principal producto a distribuir, esto permitiría el trabajo colaborativo al ser un punto de encuentro que favorece a la población que habita en la cuenca principalmente centros educativos, las entidades gubernamentales interesadas en la gestión integrada del recurso hídrico en la cuenca del río Dagua y al grupo de investigación Territorios, siendo una herramienta que permite la difusión de información actualizada.

Si bien internet se asocia a ámbitos urbanos 
también establece una relación con el ámbito rural cuando se usa para difundir información de investigaciones realizadas en áreas rurales como lo es una cuenca hidrográfica. En Colombia la información geográfica es de limitado acceso debido a que se concentra en entidades dedicadas a la generación de la misma y no ha sido creada para su difusión. Los sistemas de información geográfica en la web (SIG-WEB, geoportales, geovisores, mapas interactivos, mapas virtuales) se convierten en una herramienta de importancia para la geolocalización y consulta de información detallada de una ubicación en particular en este caso lo concerniente a la geografía del agua en el Valle del Cauca. La implementación del sistema de información geográfica-web permite: generar información de la cuenca del río Dagua, la consulta de información para la toma de decisiones en la gestión del recurso hídrico, aporta a la geografía del agua, facilita el compartir información generada con la población que habita en la cuenca mediante un proceso de difusión acompañada, mostrar las variables identificadas como contaminantes en la cuenca del río Dagua, generar un sistema de información centralizado que permita a las organizaciones la circulación de la información geográfica producida en investigaciones asociadas a la cuenca.

\section{LA CUENCA HIDROGRÁFICA DEL RÍO DAGUA}

La cuenca hidrográfica del río Dagua se localiza en el suroccidente colombiano, en el costado occidental del departamento del Valle del Cauca, cubre los municipios de Dagua, La cumbre, Restrepo y Buenaventura. Este río tiene una longitud de $110 \mathrm{~km}$ y la cuenca tiene un área de 142.500 ha. El río tiene su origen en el costado occidental del parque nacional

Farallones de Cali a una altura de 2.200

m.s.n.m, drena hacia el Océano Pacífico. En el

área se encuentran zonas secas con

precipitaciones de 700 milímetros al año en la parte alta y en la parte baja las precipitaciones ascienden hasta 7.000 milímetros al año.

La forma de la cuenca corresponde a un triángulo equilátero, presenta un sistema hidrológico de respuesta rápida y de características torrenciales. Presenta una red hídrica de tipo dendrítico o subdendrítico, siendo una red densa de drenajes cortos que se concentran hacia el cauce principal en corto tiempo y la mayor densidad de drenajes en la cuenca se concentran hacia la margen derecha del cauce principal. La red de drenaje en la parte alta de la cuenca es muy densa y está determinada por las condiciones topográficas y fisiográficas. Presenta un patrón de drenaje transversal donde los cursos de agua corren más o menos en sentido perpendicular entre sí.

En la parte alta de la cuenca se encuentra la reserva de Bitaco y a lo largo de la cuenca se encuentra bosque seco y bosque tropical, bosque de segundo crecimiento, colinas altas y bajas, terrazas y llanura costera. Los usos del suelo en el área de la cuenca corresponden a bosques, pastos, rastrojos y agricultura. Presenta baja densidad poblacional compuesta por minoría indígena, blancos, mestizos, mulatos y etnia afro descendiente los cuales laboran en actividades como la minería artesanal, agricultura familiar, comercio, actividades agrícolas y turismo. Esta cuenca es de gran importancia por su localización estratégica al estar cerca de la ciudad de Buenaventura y al pacifico donde se localiza uno de los puertos marítimos importantes para el país (Figura 1). 
Fuente: Elaboración propia.

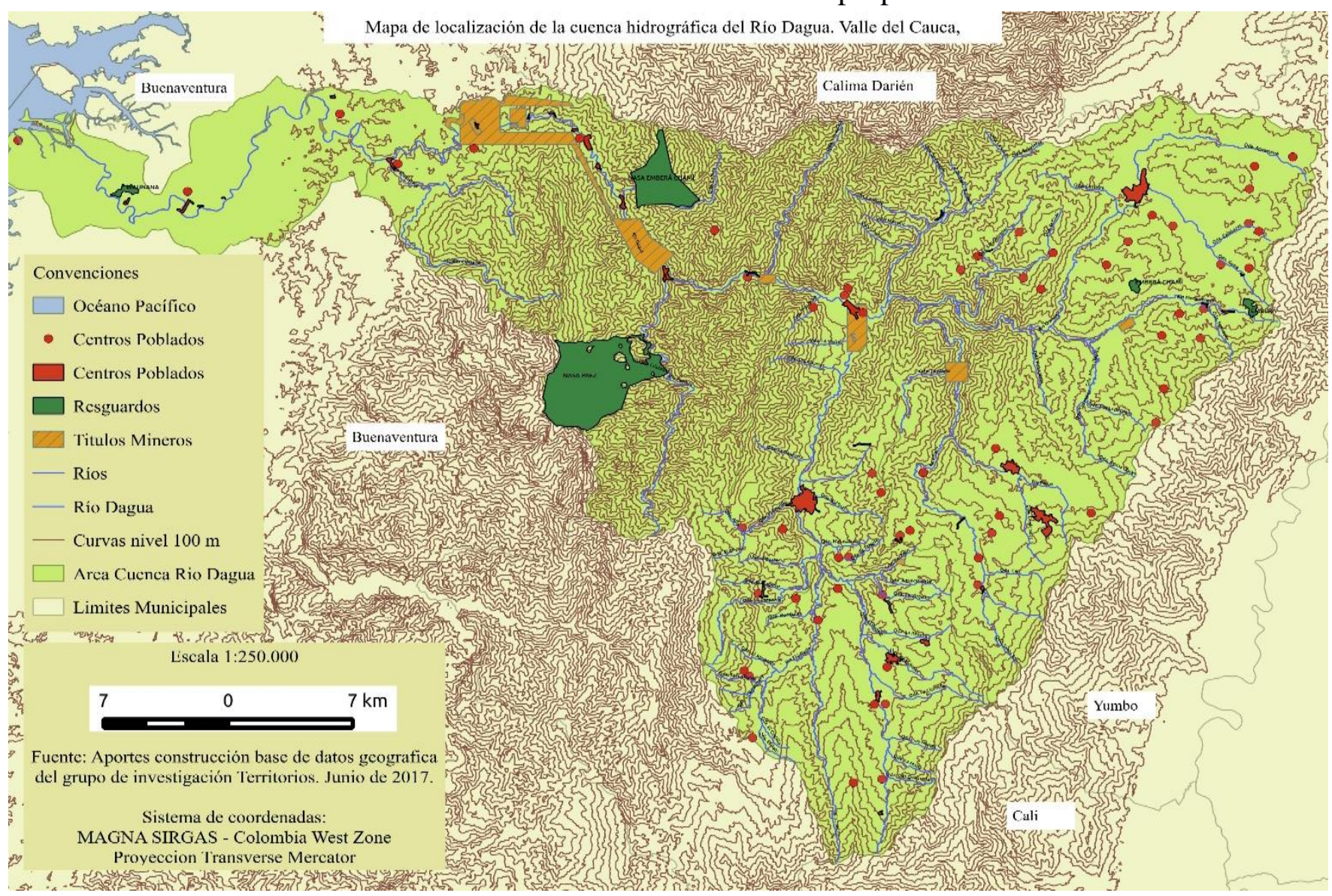

Figura 1. Mapa de localización área de la cuenca hidrográfica del río Dagua.

Entre las actividades que contribuyen a la afectación ambiental sobre la cuenca hidrográfica y las fuentes de agua podemos encontrar situaciones asociadas al uso de los suelos, la deforestación, los residuos contaminantes para las fuentes de agua que resultan de las actividades domésticas y la explotación minera principalmente la extracción de oro la cual ha generado afectación sobre la parte baja de la cuenca provocando deterioro en el cauce del río y afectación sobre la dinámica natural de este, también la mala disposición de los residuos sólidos y líquidos, la explotación ilegal de oro, la construcción de la vía Cali-Buenaventura, la falta de un sistema de recolección de basuras, así como, afectación negativa en los procesos de sedimentación los cuales terminan afectando el puerto de Buenaventura por la carga de sedimentos que son transportados por el río Dagua (Tabla 1). 
Tabla 1. Actividades contaminantes de las fuentes hídricas en la cuenca del río Dagua.

\begin{tabular}{|l|l|}
\hline Cuenca alta del río Dagua & Cuenca baja del río Dagua \\
\hline -La actividad doméstica (vertimientos de aguas & -Presencia del basurero del Distrito en la \\
residuales que se descargan de manera directa a & quebrada E1 Venado en la vereda Córdoba. \\
los causes de agua) & -Mala disposición de los residuos sólidos y \\
-La actividad agrícola & líquidos. \\
-El aumento de las construcciones en cauces de & -La explotación ilegal de oro. \\
los rios y nacimientos de agua. & -Presencia de mercurio en el agua y el \\
-Instalación e incremento de granjas avícolas, & ambiente. \\
porcinas & -La construcción de la vía Cali-Buenaventura \\
-Cultivos con uso de fertilizantes y pesticidas. & -Falta de un sistema de recolección de basuras. \\
-Actividades residenciales & -Contaminación agregada a las fuentes de agua \\
-Actividades económicas y productivas & en \\
-Carencia de un sistema de alcantarillado. & la parte alta de la cuenca. \\
-Carencia de tratamiento de aguas residuales. & -Altos niveles de sedimentación. \\
-Deforestación para la expansión de actividades & \\
agrícolas. & \\
-Paso del oleoducto de Ecopetrol. & \\
-Construcción de la doble calzada Cali- & \\
Buenaventura. & \\
-Altos niveles de sedimentación. & \\
\hline
\end{tabular}

Fuente: Grupo Territorios Informe año 2016, Investigación recurso hídrico de las cuencas de los ríos Cauca y Dagua recuperado Cali, Valle del Cauca, occidente 2015/5 - 2018/12

\section{ASPECTOS}

\section{METODOLÓGICOS PARA LA CONSTRUCCIÓN DEL SIG WEB}

En el desarrollo de aplicaciones "web mapping” el uso de software Open Source es una alternativa en el manejo y difusión de información geoespacial porque son múltiples las formas en que puede ser usada y son muchas las personas que pueden emplearla, el código abierto garantiza el acceso y contribuye a mejorar las necesidades sociales. Las ideas de la OSGeo (Fundación para el Código Abierto Geoespacial) y la OGC (Open Geospatial Consortium) promueven la difusión y construcción de software geoespacial abierto que contribuyan a la creación de la gran comunidad geoespacial, estas organizaciones han creado estándares y normas para el manejo de formatos y datos espaciales, el uso de los datos o información geográfica debe promover que pueda ser usada libremente y puesta a disposición de la gran comunidad global.

La tecnología "web mapping” es una 
herramienta que facilita la construcción y difusión de datos geoespaciales, permite representarlos en un mapa digital sobre el cual se hace la codificación y sobre la información geográfica sobre la cual se va a trabajar para poder obtener un resultado. Si bien la creación de una IDE (Infraestructura de Datos Espaciales) requiere un conjunto de recursos para gestionar la información geográfica disponible en internet y que cumplan una serie de normas, especificaciones, protocolos, interfaz, etc. que le permitan a un usuario cubrir sus necesidades con el uso de herramientas geoespaciales. Una IDE usando web mapping significa la creación de una aplicación web; una herramienta útil, de aplicabilidad para el desarrollo de un proyecto en este caso sobre la información de la cuenca hidrográfica del río Dagua.

Es una herramienta que puede ser utilizada accediendo a un servidor web a través de internet y mediante un navegador, está codificada y soportada por un navegador. En este caso se usa la Librería de código abierto Leaflet de Javascript escrita y creada por Vladimir Agafonkin, la cual permite crear mapas interactivos para la web y para el entorno móvil de manera práctica debido a que existe una documentación y estructura de código para crear los mapas. Con esta biblioteca se pueden usar mapas base de Google, Esri, OpenStreetMap, operar y modificar datos vectoriales y datos ráster, así como hacer uso de múltiples herramientas para crear mapas.

Para el desarrollo del geovisor fue necesario centrarse en la información geográfica existente asociada a la cuenca hidrográfica del río Dagua, posteriormente se hace una revisión detallada para conocer el tipo de datos que contiene las capas de información, se hace una clasificación de las variables correspondientes a condiciones geográficas, temporalidad, variables de componente social, morfología, geofísicas, ecológicas, cobertura y usos del suelo, ambientales, culturales y económicas. Seguidamente se hace selección de variables que cumplan con las condiciones para poder ser utilizadas en la creación de la estructura de datos, se definen características de sistema de referencia, formato, geoprocesamiento $\mathrm{y}$ definición de formato final usando el software libre Quantum Gis (QGIS, 2018). Por último, se hace la conversión del archivo .shp de ESRI a formato GEOJSON y posteriormente a un archivo de tipo Javascript (Figuras 2 y 3 ). 
Fuente: Elaboración propia.

METODOLOGIA

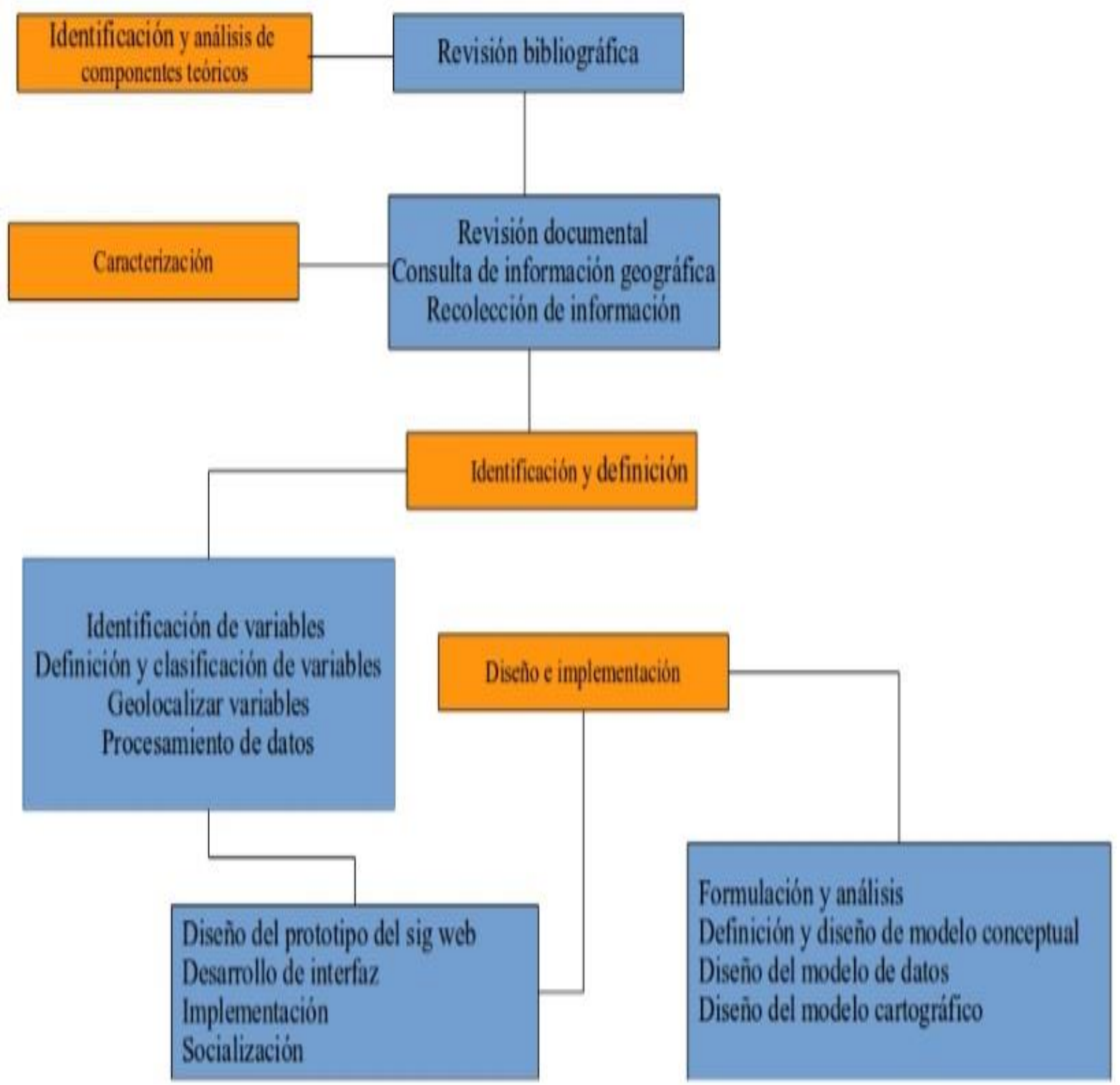

Figura 2. Metodología empleada para desarrollar el geovisor de la cuenca del río Dagua. 
Fuente: Elaboración propia.

\section{METODOLOGÍA PARA EL PROCESAMIENTO DE INFORMACIÓN}

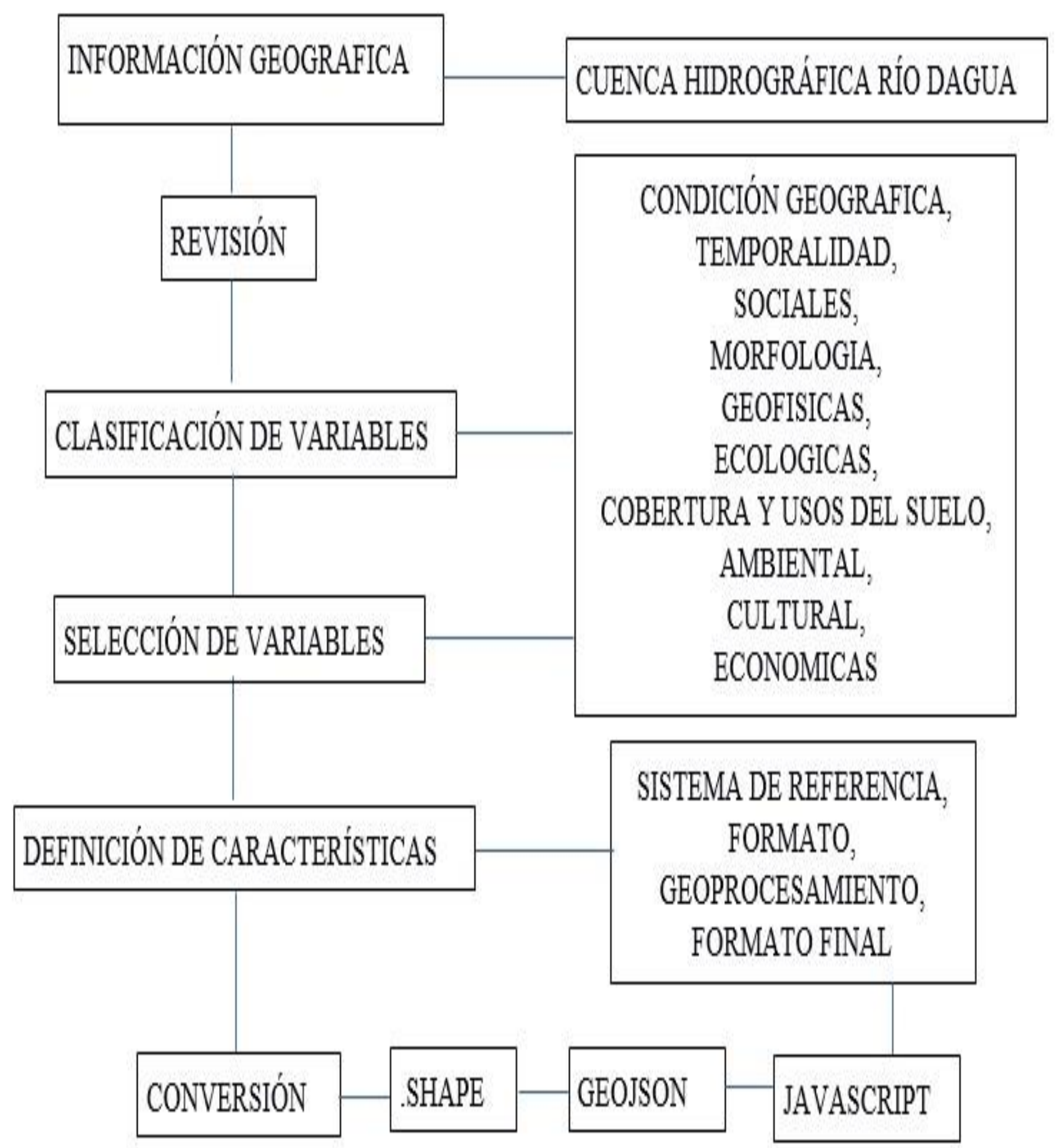

Figura 3. Metodología para el procesamiento de la información geográfica de la cuenca del río Dagua. 
Para la generación de la fuente de datos con información geográfica de la cuenca del río Dagua se utiliza el formato GeoJson ${ }^{1}$ el cual sirve para codificar datos sobre características geográficas usando JavaScript Object Notation (JSON) [RFC7159]. Las características geográficas no necesitan ser cosas físicas; cualquier cosa con propiedades que están delimitadas en el espacio puede considerarse una característica. GeoJSON proporciona un medio de representar tanto las propiedades como la extensión espacial de las características. GeoJSON es muy importante en muchas bases de datos espaciales, APIs web y plataformas de datos abiertos. Los objetos GeoJSON sólo representan características geográficas y no especifican asociaciones entre características geográficas y dispositivos, usuarios o instalaciones particulares. Cualquier asociación con un dispositivo, usuario o instalación en particular requiere otro protocolo. Por esta razón, para poder procesar la información y poder mostrarla es necesario el uso de la codificación Javascript (.js) el cual es un lenguaje de programación ligero, con funciones de primera clase que comprende una secuencia de comandos para páginas web, este lenguaje permite que información pueda ser estructurada para luego ser interpretada en modo lenguaje de máquina, su funcionamiento consiste en que los programas creados son scripts embebidos en un archivos html los cuales son ejecutados en un navegador web, los scripts son una secuencia de comandos $u$ órdenes las cuales son llamadas desde un archivo html, por esta razón se puede utilizar grandes cantidades de información que traducida en la estructura de este lenguaje luego puede ser impresa en una pantalla. Javascript

\footnotetext{
${ }^{1}$ La especificación del formato GeoJSON está disponible en http://geojson.org.
}

utiliza una estructura de funcionamiento y por los aportes de la comunidad de desarrolladores han creado una serie de librerías o estructuras de código fuente e interfaz que están disponibles para aplicar sobre un objeto o que pueden ser usadas para construir una aplicación.

\section{RESULTADOS}

A continuación, se describen los resultados obtenidos de la metodología empleada para el desarrollo del geovisor.

\subsection{Formulación y análisis de requerimientos}

En el desarrollo de software existe una fase muy importante que corresponde a formular los procedimientos y requerimientos necesarios para poder desarrollar un proyecto, el cual este compuesto por una serie de actividades y tareas que se cumplen en una temporalidad determinada. La formulación y análisis de requerimientos corresponde a la fase en la cual se efectúan una serie de actividades con el propósito de comprender el problema planteado y se enuncia el resultado en una especificación técnica.

En el desarrollo de software, los requisitos son las necesidades del producto que se debe desarrollar, por esto en la fase de análisis de requisitos se deben identificar las necesidades y documentarlas, como resultado se presenta la descripción de lo que el sistema creado debe hacer. El análisis de requisitos corresponde al proceso en el cual se estudian y definen las necesidades de los usuarios. Para llegar a una definición de los requisitos del sistema hardware o software, se debe tener en cuenta la condición o capacidad que necesita el usuario para resolver un problema o conseguir un 
objetivo. El geoportal presenta las siguientes características:

\subsubsection{Sistema}

Para acceder al geoportal web se requiere sistema operativo Linux Ubuntu/Debian,Windows, conexión a internet. Navegadores web; *Escritorio: Chrome, Firefox, Safari 5+, Opera 12+, IE 7-11. Mobile: Safari for iOS 7+, Android browser 2.2+, 3.1+, 4+, Chrome para móviles, Firefox para móviles, IE10+ para Win8 devices.

\subsubsection{Interfaz}

Para el acceso a la visualización de mapas se emplea la librería Leaflet escrita en el lenguaje de programación Javascript, sus características son:

Capas: capas de fondo, wms, plugins, marcadores, ventanas emergentes, capas y vectores: Polilíneas, Polígonos, círculos, rectángulos. Imágenes, coberturas, archivos en formato GeoJSON. Funciones de interacción: Arrastre de paneo con inercia, rueda de desplazamiento zoom, pellizcar-acercar en el móvil, doble clic en el zoom, zoom al área (desplazamiento-arrastre), navegación por el teclado. Eventos: clic, mouseover, marcador arrastrando. Controles de mapa: botones de zoom, atribución, conmutador de capas, escala. Características visuales: Zoom y pan animación, animación de fondos y ventanas emergentes, muy buen diseño predeterminado para marcadores, ventanas emergentes y controles de mapa, soporte de resolución Retina. Funciones de personalización: ventanas emergentes CSS3 y controles para un fácil rediseño, marcadores basados en imágenes y HTML, interfaz simple para capas y controles de mapas personalizados, proyecciones de mapas personalizados (con EPSG: 3857/4326/3395), acceso a Plugins. Visualización: tamaño área del mapa: 800 px puede variar dependiendo del tipo de contenido que se quiera mostrar. Ventajas: la librería JavaScript permite que los contenidos de los mapas sean livianos $y$ sin dependencias externas.

Para llegar a una definición de los requisitos del sistema software, se debe tener en cuenta la condición o capacidad que necesita el usuario para resolver un problema o conseguir el objetivo que es la visualización de datos geográficos de la cuenca del río Dagua (Figura 4 y Tabla 2). 
Fuente: Elaboración propia.

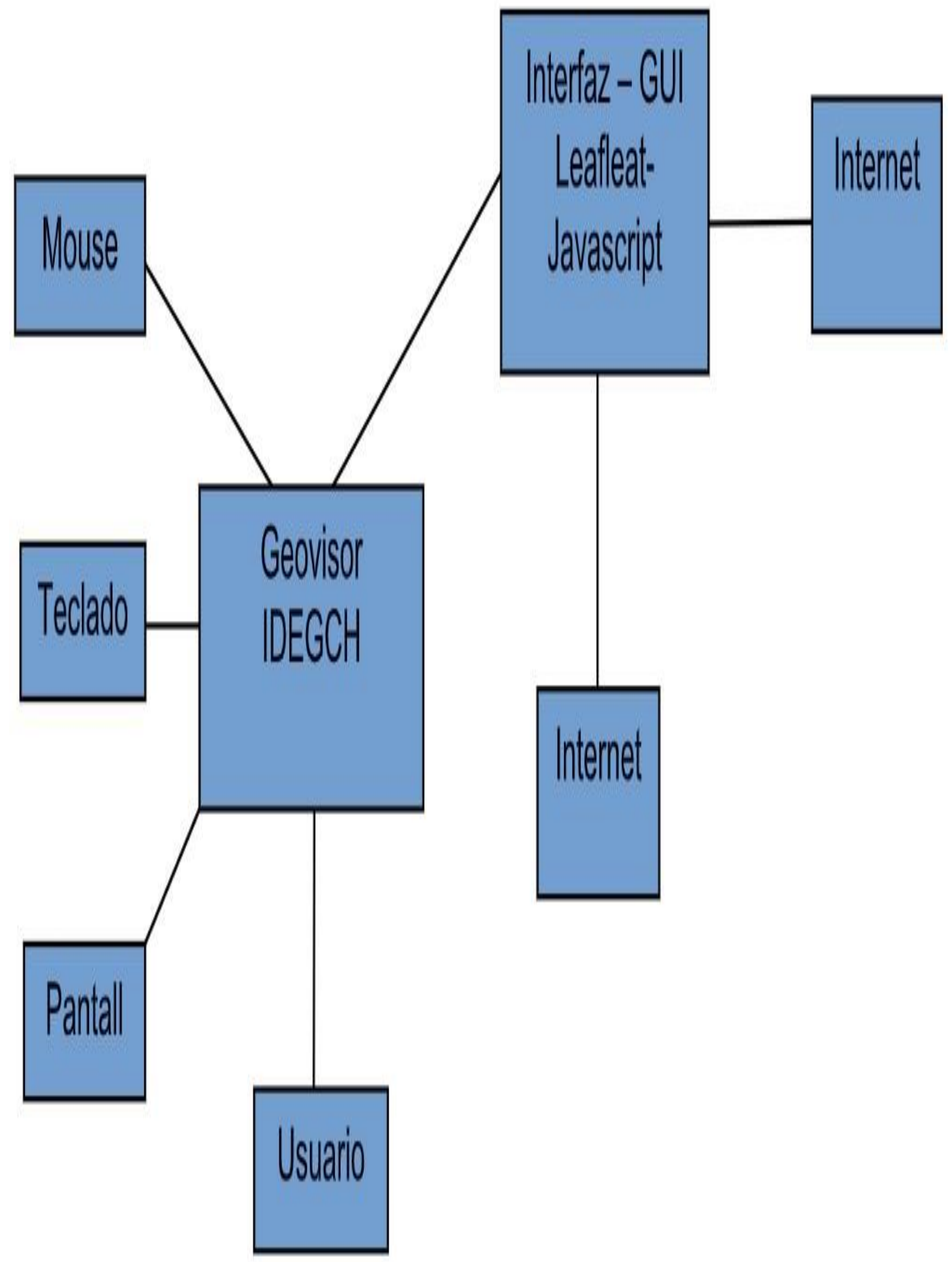

Figura 4. Modelo que muestra la interacción del usuario con la interfaz. 
Tabla 2. Requerimientos para el geovisor IDEGCH.

\begin{tabular}{|c|c|c|c|}
\hline SISTEMA & INTERFAZ & USUARIO & RESTRICCIONES \\
\hline $\begin{array}{l}\text { Sistema operativo: } \\
\text { Linux Ubuntu/Debian, } \\
\text { Windows } \\
\text { Conexion a internet. } \\
\text { Navegadores web: } \\
\text { *Escritorio: Chrome, } \\
\text { Firefox, Safari } 5+\text {, } \\
\text { Opera } 12+, \text { IE } 7-11 . \\
\text { Mobile: Safari for iOS } \\
7+, \text { Android browser } \\
2.2+, 3.1+, 4+\text {, Chrome } \\
\text { para móviles, Firefox } \\
\text { para móviles, IE10+ } \\
\text { para Win8 devices. }\end{array}$ & $\begin{array}{l}\text { Libreria Leaflet, } \\
\text { Javascript, htm15 } \\
\text { y css. }\end{array}$ & 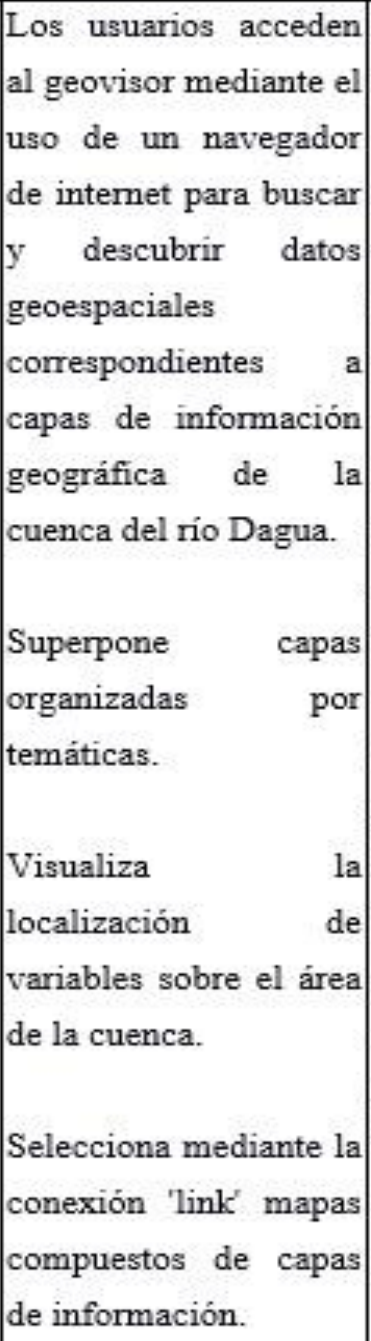 & 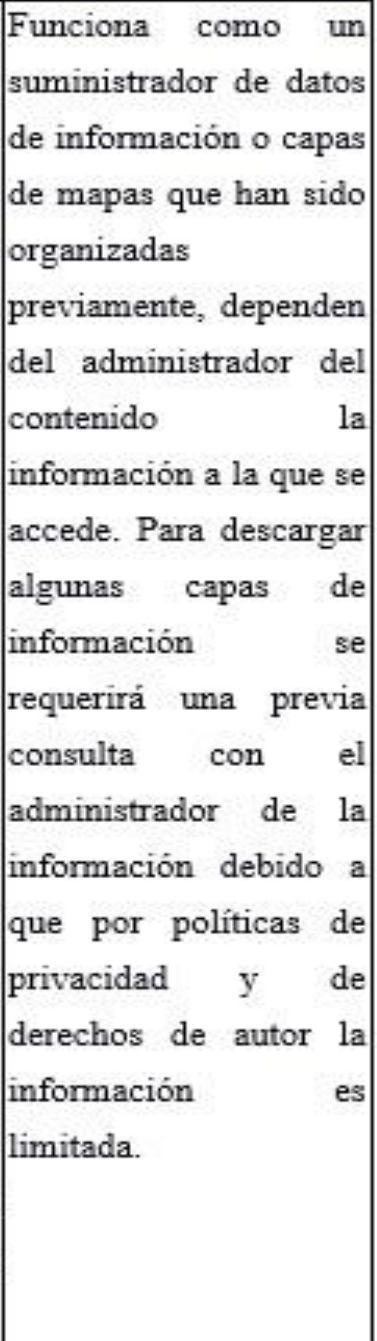 \\
\hline
\end{tabular}

Fuente: Elaboración propia.

\subsubsection{Usuarios}

Los usuarios pueden visitar el geoportal accediendo mediante el uso de un navegador de internet para buscar y descubrir datos geoespaciales correspondientes a capas de información geográfica de la cuenca del río Dagua, podrán superponer capas organizadas por temáticas y visualizar la localización de variables sobre el área de la cuenca. Podrán seleccionar distintas capas de información, superponer, determinar su utilidad y mediante la conexión 'link' podrán seleccionar mapas compuestos de capas de información para poder visualizarlos, podrán acceder a descargar las capas de información. Actividades del usuario: accede, visualiza, selecciona - busca, interactúa, compara, descarga, imagen/dato, usa la información.

\subsubsection{Administrador}

Se encarga de gestionar, organizar, cargar las capas de información y vigilar que todo funcione.

Debe solucionar los errores o fallas que tenga el sitio web. 


\subsubsection{Infraestructura}

Ordenador, internet, navegador, acceso al geoportal.

\subsubsection{Restricciones}

Funciona como un suministrador de datos de información o capas de mapas que han sido organizadas previamente, dependen del administrador del contenido la información a la que se accede. Para descargar algunas capas de información se requerirá una previa consulta con el administrador de la información debido a que por políticas de privacidad y de derechos de autor la información es limitada.

\subsection{Diseño e implementación del prototipo de sig web}

Debido a la importancia geográfica que tiene el uso de la información en la actualidad hace que casi el total de la información usada por diversas disciplinas tenga un referente geoespacial, por esta razón existe una disciplina encargada de la gestión y uso de la información georreferenciada de diferentes realidades en la superficie terrestre. Los Sistemas de Información Geográfica (SIG) los define G. Korte (2001), como se citó en Olaya (2011) "un sistema que integra tecnología informática, personas e información geográfica. Su función es capturar, analizar, almacenar, editar y representar datos georeferenciados" (p. 9). Los SIG son un conjunto de herramientas que permiten desplegar digitalmente datos del mundo real o porciones de la superficie terrestre. La información geográfica se compone de datos, los datos corresponden a un conjunto de mapas que contienen información de una porción o área terrestre que tiene la misma localización o coordenadas, lo que permite hacer análisis de sus características espaciales y temáticas. El uso de Los SIG como herramienta permiten almacenar y manipular grandes volúmenes de datos georreferenciados, realizar análisis de acuerdo a la posición geográfica, organización y administración de los datos para que sean accesibles a un grupo de usuarios, relacionar y vincular bases de datos y la posibilidad de una red colaborativa creadora de información geoespacial.

En los SIG el modelo tiene como inicio reconocer una realidad espacial correspondiente a una porción de la superficie terrestre, mediante un proceso de recolección de información a partir de imágenes digitales, gps y un sistema de referencia, esta información es recolectada por un grupo de personas las cuales mediante uso de tecnología y software transforman esta información para convertirla a datos digitales, posteriormente estos datos sufren un proceso de transformación los cuales permiten dibujar esta realidad y representarla en mapas. Entre las múltiples tecnologías es posible luego de su representación usar un método en el cual la información pueda ser compartida ya sea física o digital por un grupo de usuarios que la requieren para diversas situaciones que den solución a problemas (Figura 5). 
Fuente: Elaboración propia.
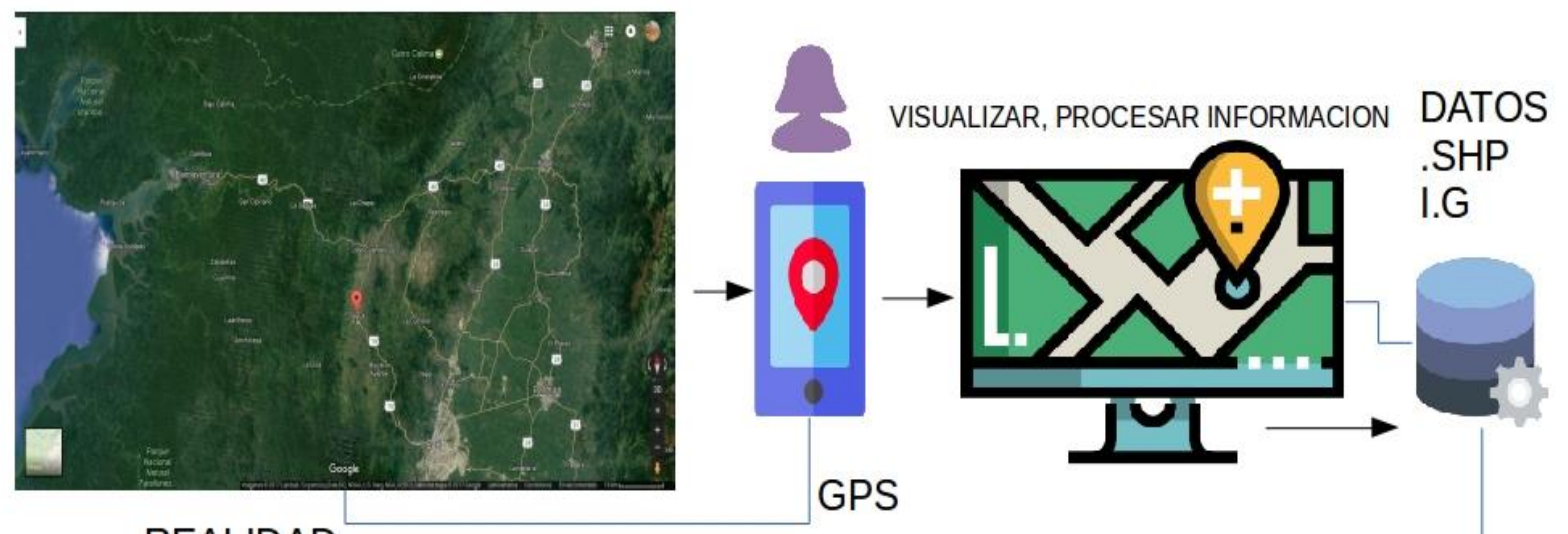

REALIDAD

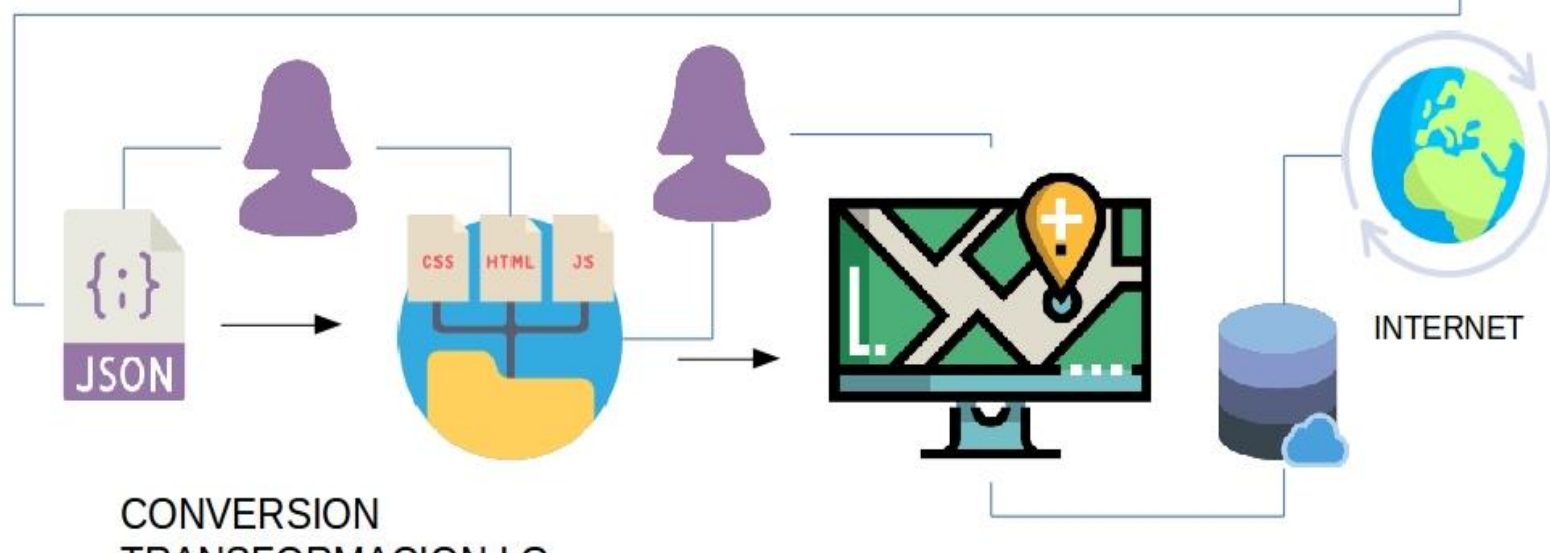

TRANSFORMACION I.G

\section{WEB MAPPING}

Figura 5. Ciclo y componentes de un SIG- WEB

\subsection{Diseño de modelo de datos del SIG y el modelo cartográfico}

El geovisor IDEGCH es una herramienta creada con el fin de tener una representación cartográfica de la realidad espacial asociada a la cuenca hidrográfica del río Dagua, constituye la representación de objetos y variables especializadas. Es la descripción de la realidad traducida a un lenguaje lógico que permite visualizar en la pantalla de un ordenador o dispositivo electrónico un conjunto de mapas.

\subsection{Modelo de datos}

Realidad: La realidad a ser representada es una cuenca hidrográfica que corresponde a una unidad de análisis para procesos de panificación y administración en la Gestión Integral del recurso hídrico en Colombia. La cuenca hidrográfica es un área de 142.500 ha asignada al río Dagua, ubicada en el occidente del departamento de Valle del Cauca. La cuenca hidrográfica comprende una serie de características de drenaje natural y aguas superficiales tributarias al río Dagua; está conformada por morfologías, conjunto de ecosistemas, actividades antrópicas, áreas 
protegidas, actores sociales e instrumentos de gestión.

Modelo conceptual: La cuenca hidrográfica del río Dagua es representada por un polígono a partir de la definición de entidades u objetos con el fin de caracterizar la porción de territorio y hacer la superposición de información para dar contenido a la representación de la realidad en el geovisor.

Entidades: Al considerar la realidad como un conjunto de objetos que se juntan en un espacio y pueden modelarse a una escala determinada, las entidades permiten hacer una abstracción que puede dibujarse en un plano según sus dimensiones.

Son entidades a ser representadas: El Área de la cuenca, subcuencas, río Dagua, red hídrica, red vial, curvas de nivel, núcleos urbanos, estaciones meteorológicas, puntos de muestreo hidrológico, áreas de reserva, enclaves, distritos de conservación, biomas, corregimientos, resguardos, comunidades negras, consejos comunitarios, títulos mineros, veredas, actividades económicas, indicadores ambientales, indicadores socio ambientales, límites municipales, figuras de ordenamiento territorial y unidades de paisaje.

Estas entidades comprenden seis categorías de información que las caracterizan para poder visualizarse en el área de la cuenca, corresponde a lo siguiente:

Identificador: Cada una de a entidades tiene un id que la identifica y permite diferenciarla de cada entidad, corresponde a un valor numérico y a una variable de tipo numérica y de cadena que la diferencia de otras entidades, así como su condición de objeto puntual, lineal o poligonal.

Posición: Cada entidad contiene información asociada al área y a su geometría la cual está determinada por coordenadas de longitud y latitud entre los $-76^{\circ},-77^{\circ}$ y $3^{\circ}, 4^{\circ}$.

Propiedades espaciales: Cada entidad tiene en su definición de referencia espacial el sistema de coordenadas geográficas mundial WGS84 (Sistema Geodésico Mundial de 1984), geometría tipo línea, polígono o punto e información asociada según la entidad.

Propiedades no espaciales: Cada entidad presenta variables asociadas a su descripción de tipo cualitativo y cuantitativo relacionadas con el objeto, es información utilizada para que en la visualización se permita una mejor descripción de cada entidad en el mapa.

Relaciones con el entorno: la forma como cada entidad es representada en el área de la cuenca guarda relación con la geometría de cada entidad, la forma como esta es superpuesta depende de la geometría y las coordenadas de longitud y latitud haciendo que unos objetos estén superpuestos sobre otros, así como la creación que guarda cada entidad con el tipo de información. Para esto se han agrupado las entidades de acuerdo a tipos de información o mapas, lo que permite diferenciar información social, información de áreas, información de características e información descriptiva. Todas superpuestas pero que se muestran dentro de los límites del área de la cuenca hidrográfica del río Dagua.

Modelo vectorial: En el modelo vectorial los diferentes objetos o entidades son representadas como puntos, líneas y polígonos. Par el caso de las entidades que son representadas como puntos, comprenden una referencia única de coordenadas de longitud y latitud. Para el caso de las entidades representadas como líneas corresponden a un conjunto de líneas en cadena que contienen una serie de referencias de 
coordenadas de longitud y latitud y para el caso de las entidades representadas como polígonos, corresponden a un conjunto de polígonos, los cuales pueden ser visualizados a partir de una serie de referencias de coordenadas de longitud y latitud.

Las entidades en el modelo vectorial son representadas por puntos, líneas y polígonos los cuales contienen categorías de información que permiten su representación en el modelo cartográfico, posteriormente esta información es codificada mediante elementos simples; cadenas de caracteres y números enteros y números reales en formato GeoJson y traducido a la estructura Leafleat de Javascript. La forma como se expresa cada entidad corresponde a la Tabla número 3.

Tabla 3. Representación de los datos geográficos y su transformación para ser visualizados en el geovisor.

\begin{tabular}{|c|c|c|}
\hline Modelo Vectorial & GEOJSON & JAVASCRIPT \\
\hline $\begin{array}{l}\text { Puntos: estaciones meteorológicas, } \\
\text { puntos de muestreo hidrológico, } \\
\text { veredas, centros poblados, actividades } \\
\text { económicas, indicadores ambientales, } \\
\text { indicadores socio ambientales y } \\
\text { figuras de ordenamiento territorial. } \\
\text { Lineas: rio Dagua, red hídrica, curvas } \\
\text { de nivel y red vial. } \\
\text { Poligonos: Área de la cuenca, } \\
\text { subcuencas, núcleos urbanos, áreas de } \\
\text { reserva, enclaves, distritos de } \\
\text { conservación, biomas, corregimientos, } \\
\text { limites municipales, resguardos, } \\
\text { comunidades negras, consejos } \\
\text { comunitarios, títulos mineros y } \\
\text { unidades de paisaje. }\end{array}$ & $\begin{array}{l}\text { Codificación WKT (Well } \\
\text { Known Text) que } \\
\text { corresponde a una } \\
\text { codificación o sintaxis en } \\
\text { formato ASCII } \\
\text { estandarizada diseñada } \\
\text { para describir objetos } \\
\text { espaciales expresados de } \\
\text { forma vectorial (puntos, } \\
\text { multipuntos, lineas, } \\
\text { multilineas, poligonos, } \\
\text { multipoligonos, } \\
\text { colecciones de geometria, } \\
\text { puntos en } 3 \text { y } 4 \\
\text { dimensiones. } \\
\text { Cada entidad se convierte } \\
\text { en un archivo Geojson. }\end{array}$ & $\begin{array}{l}\text { Entidades: Cada entidad } \\
\text { (puntos, multipuntos, } \\
\text { lineas, multilineas, } \\
\text { poligonos, } \\
\text { multipoligonos, } \\
\text { colecciones } \\
\text { geometria) se convierte } \\
\text { en una sentencia Var } \\
\text { que corresponde a } \\
\text { declarar una variable a } \\
\text { la cual se le asignan un } \\
\text { valor que le permite ser } \\
\text { ejecutadas. }\end{array}$ \\
\hline
\end{tabular}

Fuente: Elaboración propia. 


\subsection{Geovisor IDEGCH.}

El geovisor desarrollado presenta una interfaz con las siguientes características: el encabezado se compone de un logo que lo identifica y cuatro pestañas: inicio, mapas, explicación del proyecto e información de contacto. En la sección de mapas muestra la opción para visualizar 10 mapas de información (mapa de subcuencas, mapa de asentamientos, mapa de cartografía social, mapa de biomas, mapa de estaciones de muestreo, mapa de unidades de paisaje, mapa de áreas protegidas, mapa de unidades de paisaje, mapa de áreas de reserva, instrumentos de gestión y susceptibilidad de erosión) haciendo click en cada mapa. En el contenido principal se puede visualizar el contenido del mapa desarrollado, tiene tres opciones para la interacción que son pestaña de zoom, una pestaña para cargar archivos en formato GeoJson, Kml y Gpx que pueden visualizarse en el mapa y una pestaña con las capas de información que compone el mapa, muestra opción de capas base correspondientes a vías, topografía y satélite y la opción de capas de mapa las cuales podrán ser seleccionadas y deseleccionadas para interactuar y visualizar la composición de mapas. El Geovisor se encuentra disponible en la dirección: www.idegch.org el cual puede ser consultado para visualizar los datos geográficos asociados a la cuenca hidrográfica del río Dagua (Figuras 6, 7 y 8).

Fuente: http://www.idegch.org/

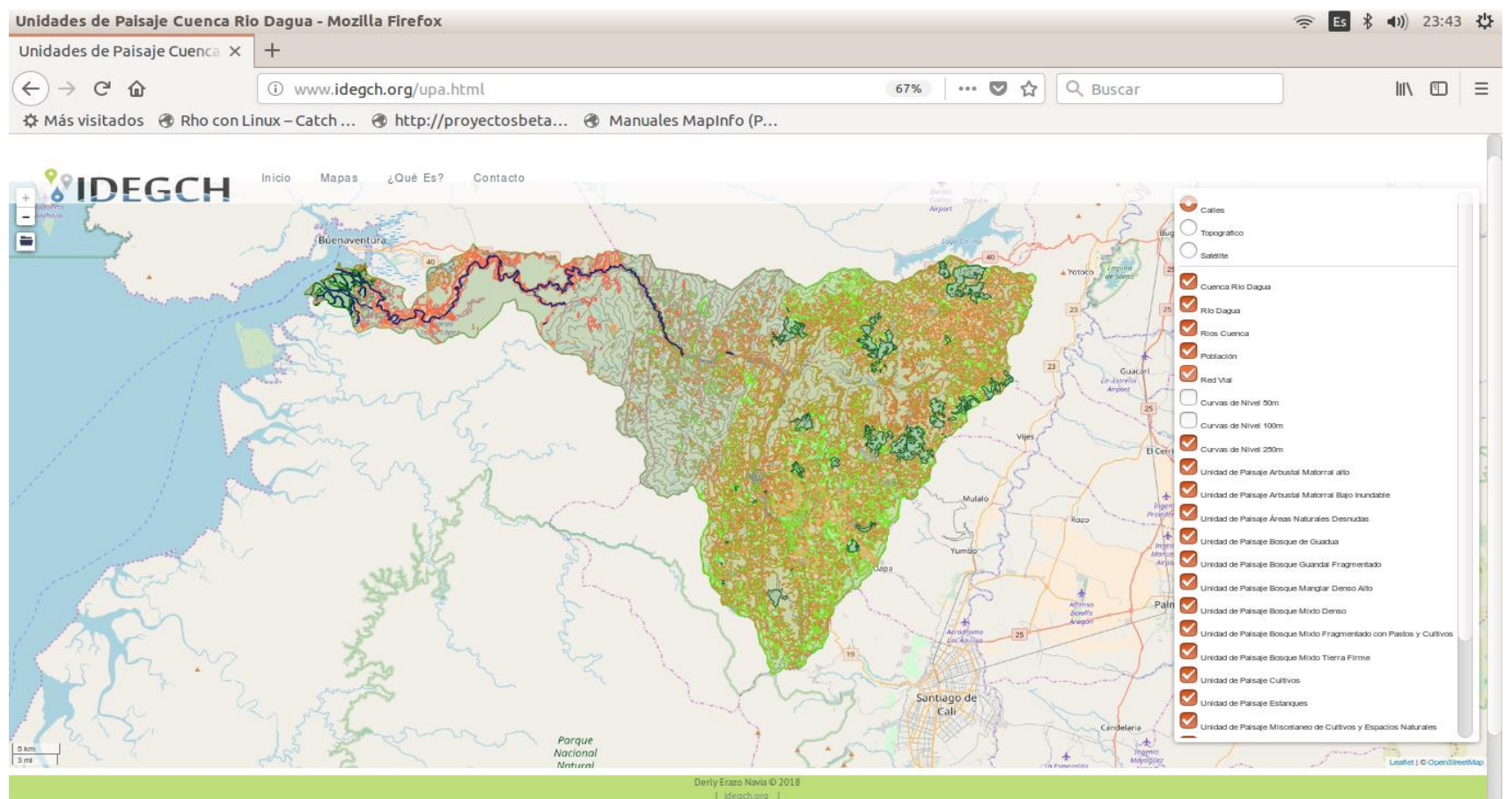

Figura 6. Visualización del mapa de unidades de paisaje presentes en el área de la cuenca del río Dagua. 
Fuente: http://www.idegch.org/

\section{IDEGCH}

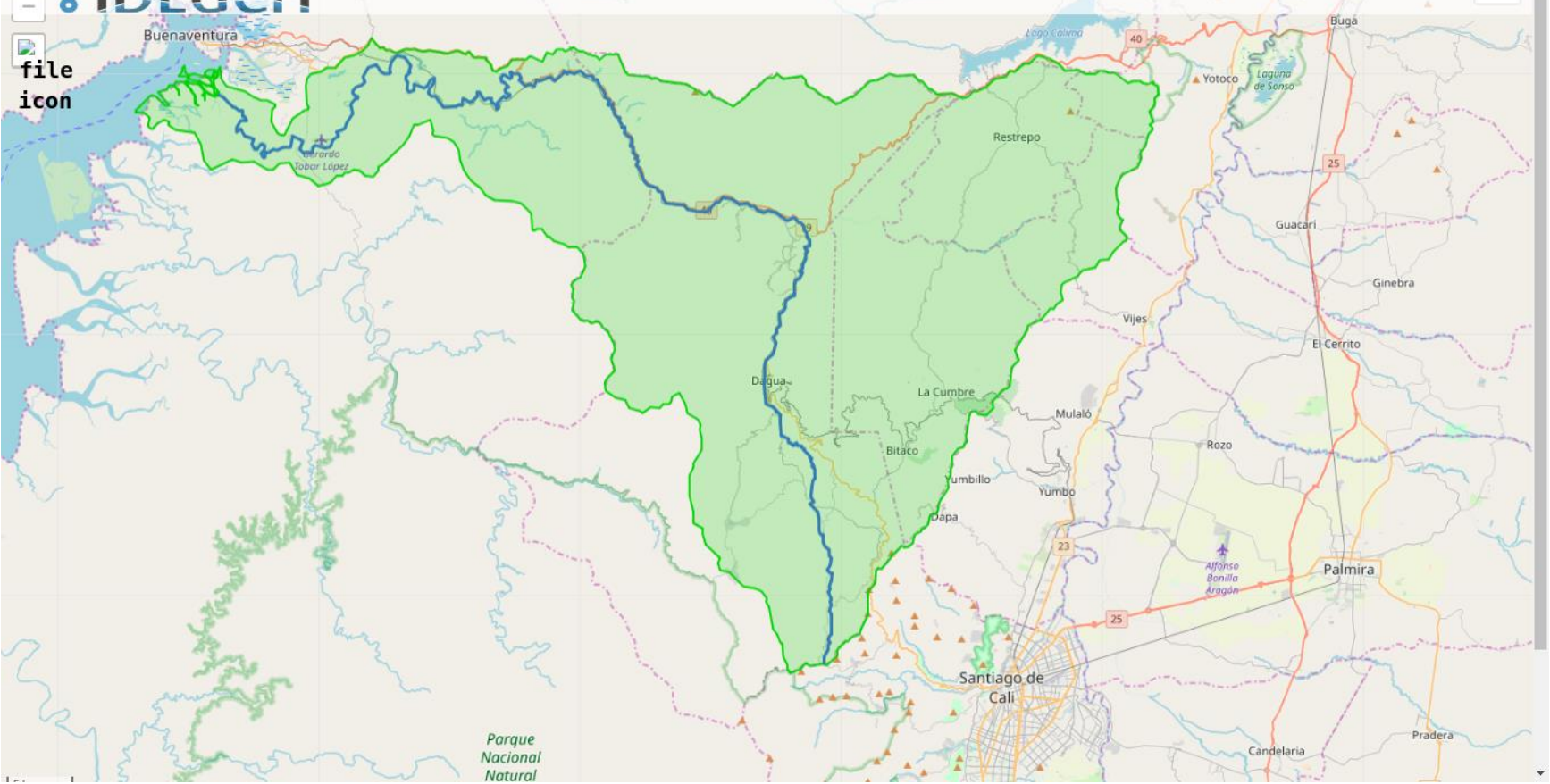

Figura 7. Vista general del área de la cuenca del río Dagua al ingresar al geovisor IDEGCH.

Fuente: http://www.idegch.org/

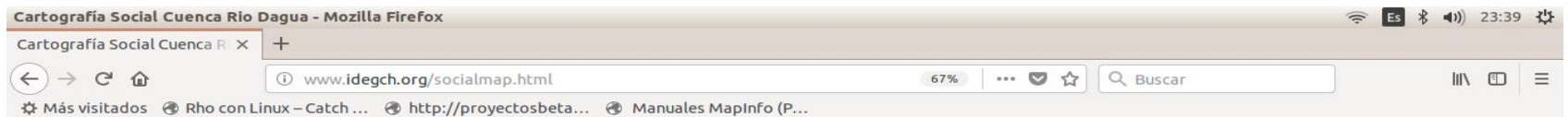

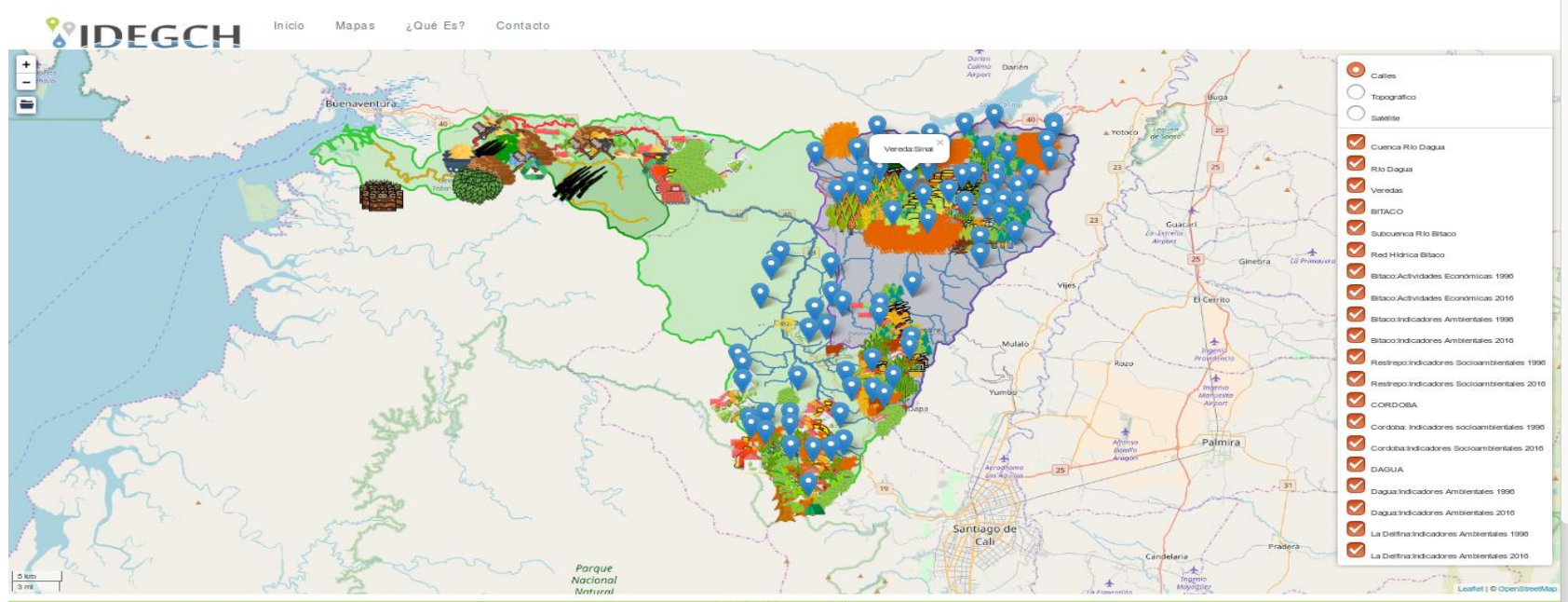

Figura 8. Vista del mapa que contiene información social de la cuenca y las principales situaciones en dos periodos de tiempo 1990 y 2016. 


\section{CONCLUSIONES}

El desarrollo del Geovisor IDEGCH permite la visualización de información geográfica asociada a la cuenca hidrográfica del río Dagua, permitiendo al usuario conocer la representación cartográfica de la cuenca y descubrir los elementos que la componen a partir de la visualización de mapas.

El geovisor tiene limitaciones al depender de la actualización de información para cada una de las capas, lo cual exige que se dé una continuidad en la generación de información asociada a la cuenca lo que requiere que se esté realizando trabajo de campo para poder recopilar datos y poder actualizarlos, esto pensado en que pueda seguirse alimentando la base de datos, de lo contrario los mapas se desactualizarían.

Un sig web presenta una posibilidad muy importante para efectuar estudios en diversas áreas que muestren detalles espaciales o geográficos que contribuyan a la gestión del recurso hídrico en una cuenca hidrográfica.

La interfaz gráfica fue diseñada con el objeto de permitir al usuario poder visualizar la información agrupada en mapas de fácil interacción.

\section{REFERENCIAS BIBLIOGRÁFICAS}

Buzai, G. D. (2014). Geografía, complejidad e investigación aplicada. Boletín de Estudios Geográficos, (102), 46-66. Recuperado de http://bdigital.uncu.edu.ar/objetos digita les/6808/004-buzai-beg-102.pdf.
La aplicación de herramientas tecnológicas para la elaboración cartográfica digital usando el web mapping permite evidenciar que es posible contribuir a una nueva geografía aprovechando la red global de internet y usando herramientas tecnológicas de código abierto. Se considera importante el uso de web mapping por el bajo costo, librerías bien documentadas. Manipular datos geográficos usando código abierto hace que los geógrafos no dependamos de límites impuestos por empresas de software GIS licenciado.

El web mapping contribuye a la creación de una red de desarrolladores que impulsan la cartografía digital como una nueva practica que contribuye a crear un territorio global, permitiendo el acceso a la información para posibles investigaciones futuras en el campo de la generación de información geográfica. Sería importante poder aplicar este modelo de representación geográfica a otras cuencas hidrográficas en el departamento y en el país.

Castells, M. (2003). La era de la información. Economía, sociedad y cultura. El poder de la identidad Vol. II. México: Alianza editorial.

Korte, G. (2001). The GIS Book (5th Ed. Rev.). Autodesk Press.

GeoJSON. (2016). (Versión RFC 7946) [Software]. Recuperado de http://geojson.org/.

JSON. (2018). (Versión RFC7159) [Software]. 
Recuperado de https://tools.ietf.org/html/rfc7159.

Librería Leaflet. (2019). (Versión 1.5.1) [Software]. Recuperado de http://leafletjs.com/.

Negroponte, N. (1995). Being Digital (Ser Digital o Mundo Digital) Edición en español. Barcelona: Ediciones B.S.A.

OGC. (2018). Open Geospatial Consortium. (Versiones WFS 1.1, WFS 2.0, WMS 1.3 y $S O S$ 2.0) [Software]. Recuperado de http://www.opengeospatial.org/.

Olaya, V. (2011). Sistemas de información Geográfica. Recuperado de https://www.icog.es/TyT/files/Libro_SI G.pdf.

OpenStreetMap. (2018). (Versión Overpass API v0.7.55) [Software]. Recuperado de https://www.openstreetmap.org/.

OSGeo. (2018). The open source geospatial foundation (Versión gvSIG Desktop 2.4) [Software]. Recuperado de https://www.osgeo.org/.

QGIS. (2018). (Versión OSGeo4W-1.5.013926) [Software]. Recuperado de https://www.qgis.org/es/site/. 